\section{Opinions of Landscape Roses Available for Purchase and Preferences for the Future Market}

\author{
Tina M. Waliczek ${ }^{1,4}$, Dave Byrne ${ }^{2}$, and Don Holeman ${ }^{3}$
}

ADDITIONAL INDEX WORDS. disease resistance, flower color, flower size, fragrance, recurrent blooming, Rosa $\times$ bybrida, rose breeding

\begin{abstract}
$\overline{\text { Summary. Rose (Rosa } \times \text { bybrida) breeders historically have bred plants based on what }}$ they personally have deemed attractive and traits required by growers to produce the crop successfully. End-user preferences were not formally considered in breeding decisions. The purpose of this study was to investigate growers' and consumers' opinions of roses available on the market and preferences for future roses coming into the market. A web-based survey tool was developed to measure the attributes consumers were considering in purchasing and growing rose plants, their knowledge of diseases and pests, and their hopes for new plants coming to market. A link was sent to horticultural group mailing lists as well as distributed through personal e-mail lists, Facebook, and a news release from Texas A\&M University. The survey was posted for 4 months. It included $\approx 66$ questions and took 30 minutes or more to complete. More than 2000 responses were received from rose growers and nursery consumers worldwide. The respondents preferred roses that were disease resistant, with fragrant, abundant, red, and everblooming flowers. The ideal height of the preferred rose shrubs was waist to shoulder-height. Differences were found in preferences between experienced rose growers and those who were not affiliated with rose associations on variables such as the need to use chemicals to manage diseases, the importance of foliage glossiness and large vs. small blooms, the value of roses in the garden setting, the level of difficulty roses pose in growing situations, and the willingness to pay more for a rose shrub in comparison with other garden plants. Differences also were found among age groups and preferences for flower color, fragrance, foliage color, and foliage glossiness. This information could be helpful in targeting marketing of roses.
\end{abstract}

$\mathrm{R}$ oses are members of the Rosaceae family, the largest and most economically important horticultural family in the world (Zlesak, 2006). Records indicate roses were cultivated as long as 5000 years ago (Guoliang, 2003; Widrlecher, 1981 ) in Europe and China. Gardeners grew them to meet practical needs such as for oils and medicine (Widrlecher, 1981), but the rose flower also is considered so beautiful that it has been regularly mentioned in poetry, religion, and represented in art and sculpture throughout the centuries (Cucciniello, 2008). In addition, roses are considered symbolic in many cultures, representing various ideas often based on their color (Hopler, 2017).

The domesticated rose is the world's most popular garden and cut-

${ }^{1}$ Department of Agriculture, Texas State University, San Marcos, TX 78666

${ }^{2}$ Department of Horticultural Sciences, Texas A\&M University, College Station, TX 77843

${ }^{3}$ Rose Hybridizer Association, Enfield, CT 06082

${ }^{4}$ Corresponding author. E-mail: tcl0@txstate.edu.

https://doi.org/10.21273/HORTTECH04175-18 flower, with thousands of cultivars available (Debener and Byrne, 2014). Roses are grown in greenhouses for the florist industry to produce both cut flowers and potted specimens (Pemberton et al., 2003; Short and Roberts, 1991). Garden, landscape, or shrub rose is a term used to describe those roses that are used outdoors in the landscape instead of as a potted flowering disposable plant or as a cut flower (Pemberton and Karlik, 2015). Garden roses exist in many forms and include hybrid teas, shrubs, and polyanthas, displaying a wide range of flower colors and forms and thus serve a multitude of landscape uses (Pemberton and Karlik, 2015).

Sales of roses in 2014 in the United States generated \$203.5 million, producing 36.6 million plants by 1808 growers (U.S. Department of Agriculture, 2015). According to the Green Industry Research Consortium National Survey (Green Industry Research Consortium, 2013), roses contributed $3 \%$ of overall sales among 18 horticultural production crop categories of the $\$ 25.9$ billion green industry value. Rose industry sales equate to contributions to the U.S. economy of about $\$ 777$ million (Green Industry Research Consortium, 2013). Most roses (65\%) are sold through retail outlets, with the remaining $35 \%$ of rose sales coming from landscape services (Green Industry Research Consortium, 2013).

Selection of rose types available to consumers is relatively limited, with big-box stores as well as retail garden centers selling mainly the most popular cultivars (Hutton, 2012). Often, when new rose cultivars have emerged, they were met with great demand (Hutton, 2012; Pemberton and Karlik, 2015). For example, 'Knock Out' and 'Simplicity' were especially well received among home gardeners and within the landscape industry (Pemberton and Karlik, 2015). However, growers sometimes find that a rose series may fall out of fashion after a few seasons and that it is a greater challenge to find a cultivar with staying power that can evolve over time to meet the needs of the consumer.

Historically, when breeding rose plants, information considered in creating new cultivars has been limited. For example, rose breeders traditionally bred plants based on what they personally have deemed appealing, or instead on variables growers have noted as vital toward the success in producing a vigorous crop (Debener and Byrne, 2014). That is not to say that some characteristics of the plants have not been noteworthy in their captivation to consumers. For instance, flower color was shown to impact consumer preference (Behe et al., 1999; Grygorczyk et al., 2014; Palma et al., 2011), and retail nurseries have used sales data to direct availability of plants with certain characteristics (Boumaza et al., 2010). Formal garden roses have less appeal compared with roses that integrate well into mixed planting beds (Hutton, 2012).

Rose producers have speculated that consumer demand is greatest for roses with high disease resistance and everblooming qualities. Other attributes mentioned as possible selling points for new cultivars of roses include a need for winterhardiness, fragrant blossoms, and new colors 
(Hutton, 2012). Related to this, research has suggested educating consumers regarding rose cultivars known to grow and perform well within their regions as important marketing tactics (Hutton, 2012). However, a formal study collecting information from consumers and growers as to their preferences for new rose cultivars has not been conducted.

The purpose of this study was to investigate growers' and consumers' opinions of roses available on the market and preferences for future roses coming into the market. The hope of the study was to determine future rose breeding endeavors to develop cultivars based on the needs of consumers and growers, thereby increasing rose use.

\section{Materials and methods}

Survey instrument. A survey was developed using a web-based survey design tool (LimeSurvey, Hamburg, Germany) and other similar industry-related instruments as models (Boumaza et al., 2010; Lombardini et al., 2008). It was evaluated for validity by rose specialists and a social scientist. A Cronbach's alpha reliability analysis determined instrument reliability to be 0.73 , which is considered an adequate level for this type of research (Gall et al., 2006).

The survey included questions/ statements in multiple sections. Seven questions were included to gather demographic information and respondents' role in the horticultural supply chain. Questions asked for respondents' home country, age, occupation, and whether he/she was a member of a rose society or rose hybridizer association.

Eleven questions asked respondents to rate the importance physical traits of roses such as flower size, flower color, number or size of thorns, and disease resistance on a five-point Likert scale (Likert, 1967) ranging from "not important at all" to "most important" in response to the question, "how important are these factors in your choice of roses?" An additional question asked the height preference of rose plants for consumers by stating, "what would you prefer most mature rose bushes to be in height?" with the response options of "head high," "shoulder high," and "waist high." Another question asked respondents to choose the flower color they most preferred their rose shrubs to have. The question provided seven color sample responses including swatches matching blue, lavender, pink, red, red-orange, orange, and yellow from which respondents could choose.

Seven questions were asked concerning valuable attributes of roses and ease of growing them. Questions were answered using a five-point Likert scale that ranged from "strongly disagree" to "strongly agree." Examples of statements included, "I prefer to grow roses that bloom throughout the season rather than just once per year," and "roses grow easily in my climate." To ascertain whether respondents were familiar with identifying common rose diseases, one section and three questions of the survey included photographs of symptoms of powdery mildew (Sphaerotheca pannosa var. rosae), black spot (Diplocarpon rosae), and rust (Phragmidium spp.) and asked respondents to correctly match the symptoms to the disease.

An open-ended area allowed respondents to answer in their own words as to the biggest improvement that breeders could make in future breeding efforts regarding roses, the greatest challenges they have in growing roses, and the plants they feel are good alternatives to roses in the garden.

SAMPLE AND ADMINISTRATION. A link was sent to convenient and accessible horticultural group mailing lists, including the American Rose Society (Shreveport, LA), the Rose Hybridizers Association (Hales Corners, WI), the Texas Nursery and Landscape Association (Austin, TX), and the Texas Master Gardeners (College Station, TX), as well as distributed through personal e-mail lists, social media, and online news releases. Respondents self-selected themselves for inclusion in the study by visiting the webpage and choosing to answer the survey. No incentive was given for participation. The survey was evaluated for problems in readability and administration and took $\approx 30 \mathrm{~min}$ or more to complete when in trials with researchers. It was posted online for 4 months in the late fall and winter.

Data ANAlysis. Data were automatically downloaded into an Excel (Microsoft, Redmond, WA) file and then analyzed using SPSS (version 21.0; IBM Corp., Armonk, NY). Descriptive statistics determined overall trends among respondents. Comparisons of those involved in rose-related associations to those not involved were made, as well as among demographic groups using analysis of variance (ANOVA) and multivariate analysis of variance (MANOVA) tests. Post-hoc least significant difference tests and/or frequencies and descriptive statistics indicated where differences were occurring. As not every person responded to all questions, missing data were coded as missing answers.

\section{Results}

SAMPLE CHARACTERISTICS. A total of 2027 responses were received. The sample included $52 \%$ (942) members of a rose society and/or involved with rose breeding and $48 \%$ (865) not associated with a formal rose-growing group. Demographic information showed $94 \%$ (1704) of respondents were U.S. residents and 93\% (1889) of respondents grew roses in some capacity. Most respondents were 55 to 69 years old [ $42 \%$ (847)] or older than 70 years old [19\% (391)]. Most respondents classified themselves as teachers $[30 \%$ (604)], professionals [8\% (167)], or as retired $[26 \%(533)]$. These sample characteristics were similar to previous studies focusing on gardeners, which indicated that these groups are often older, well-educated professionals (Sommerfeld et al., 2010).

IMPORTANT PLANT ATTRIBUTES. When respondents were asked to respond to the question, "how important are these factors in your choice of roses?" by choosing answers from a Likert scale that ranged from "not important" (1) to "most important" (5), it was somewhat surprising that respondents rated characteristics less directly related to the rose flower aesthetics. For example, when rating the importance of various characteristics, disease resistance was almost unanimously rated as being "very important" to "most important" among respondents, with $87 \%$ (1358) of respondents ranking this variable in those categories and nearly no respondents $[<2 \%(5)]$ rating this as "not important at all" (Table 1). Fragrance was the second most highly ranked attribute, with $62 \%$ (967) of respondents ranking this variable as "very important" or "most important." Flower color was rated by respondents 


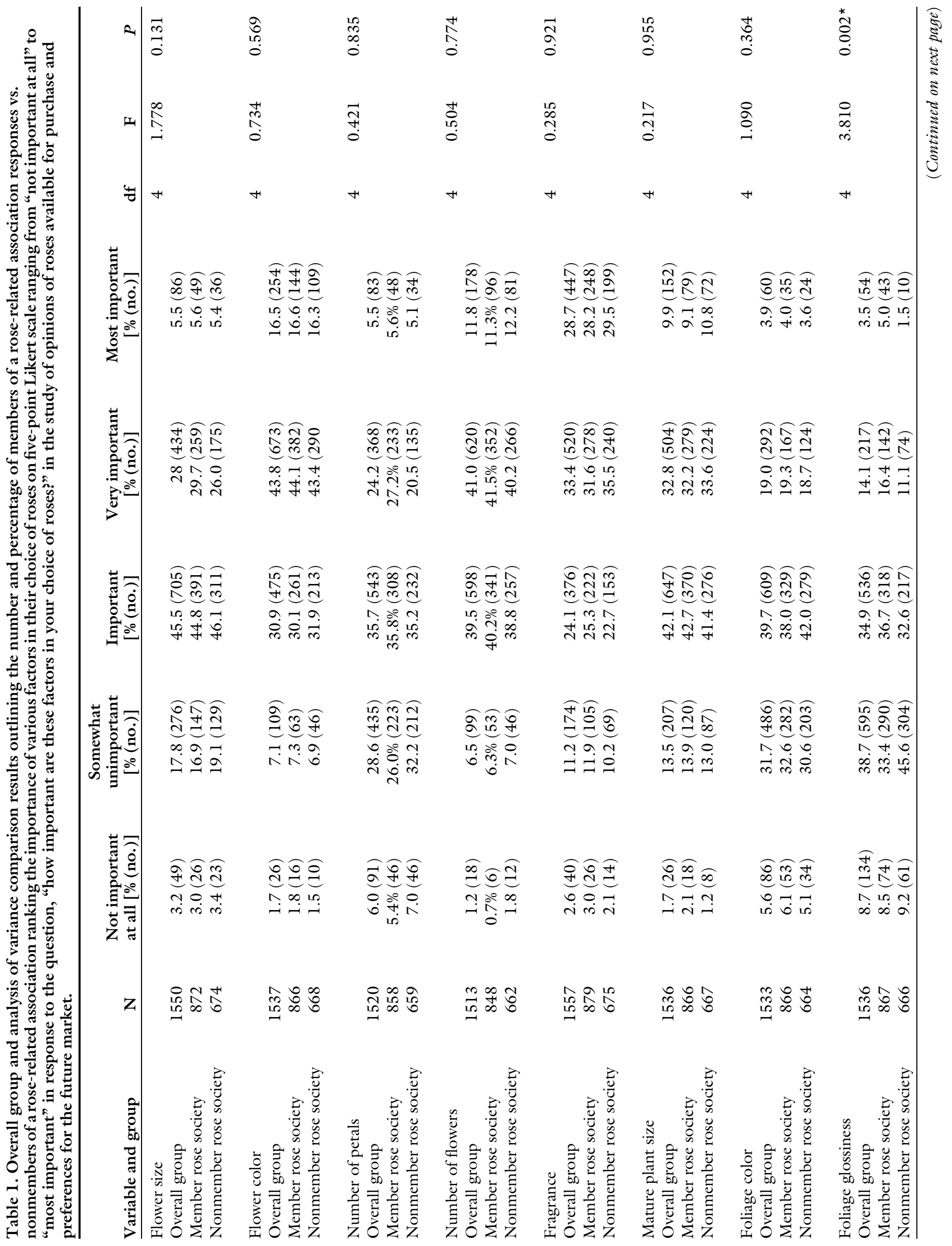




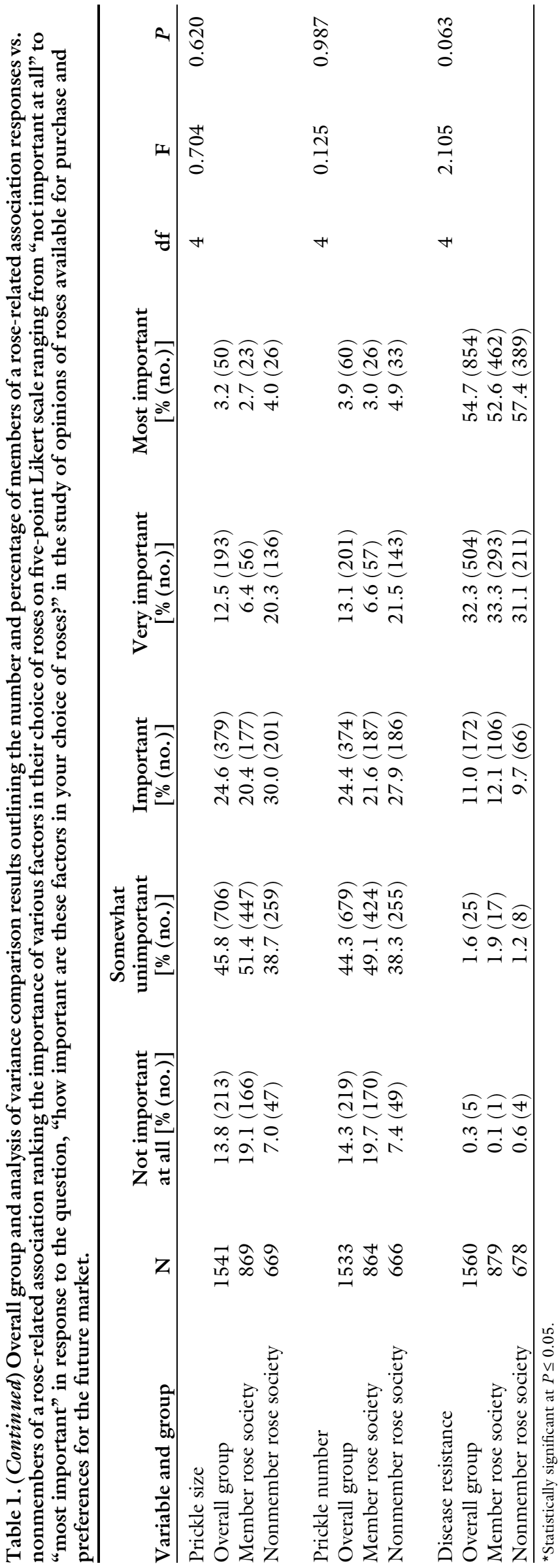

as "very important" or "most important" $60 \%$ (927) of the time. Flower size was only chosen by respondents as being "very important" or "most important" by $33 \%$ (520) of respondents (Table 1). Some of these results have been supported in previous research. An earlier study indicated that there is a low tolerance for leaf blemishes on roses (Debener and Byrne, 2014) and that advances in plant breeding are allowing the acceleration of the development of disease resistant cultivars (Debener and Byrne, 2014).

Rose breeders often historically considered rose thornlessness as being influential in consumer choice of plants (Basye, 1992), but characteristics regarding thorns were ranked as being the least important variables among those responding. Prickle size and prickle number were selected by just $16 \%$ to $17 \%(243-261)$ of respondents, respectively, as "very important" or "most important" in their choice of plants (Table 1). Other characteristics such as foliage color, foliage glossiness, flower size, and number of petals fell in between these most- and least-selected categories (Table 1 ).

When choosing a height preference for rose shrubs, most respondents preferred a rose plant that grew to waist height $[48 \%(759)]$, or to shoulder height [38\% (600)]. Most respondents preferred red roses $[30 \%$ (470)], with pink [15\% (240)] and purple $[18 \%(279)]$ being the next favorite color choices. Other color options were preferred at the following response levels: orange [12\% (190)], red-orange $[10.8 \%$ (172)], yellow $[10.5 \%(167)]$, and blue $[4.6 \%(73)]$. A previous study showed that red was the favored color among consumers and that the consideration of various shades and tints of color choices were important in determinations of consumer rankings (Grygorczyk et al., 2014). This current study was limited in that there were only seven color options shown. However, findings did support previous research.

When making comparisons between members and nonmembers of rose-related associations, no differences were found in plant-related characteristic questions except for in responses regarding the importance of "foliage glossiness." Members of rose-related associations rated this variable as being more important, with $21.4 \%$ (185) of members rating 
it as very to most important in rosepurchasing decisions vs. 12.6\% (84) of nonmembers of associations.

Plant characteristics. When respondents were asked how much they agreed or disagreed with various statements regarding pleasing rose plant characteristics and cultural requirements necessary to maintain plants, results verified previous findings in many instances (Table 2). When respondents read the statement, "I prefer roses that bloom throughout the season rather than just once per year," 89\% (1381) of respondents agreed or strongly agreed. Respondents felt neutral $[43 \%(662)]$ regarding the importance of the size of the blooms in selecting rose plants, indicating that small or large blooms are both very pleasing and marketable (Table 2).

Respondents were posed statements regarding cultural requirements needed to maintain plants. Most [62\% (946)] respondents strongly agreed or agreed that roses grew easily in their climate, and most [62\% (953)] disagreed or strongly disagreed that roses were difficult to grow (Table 2). Furthermore, most $[48 \%(730)]$ disagreed or strongly disagreed that the best way to keep plants healthy was to spray them with chemicals (Table 2). In addition, most respondents could identify common rose diseases, including black spot $[82 \%(1662)]$, powdery mildew $[82 \%(1662)]$, and rust $[93 \%$ (1764)], and most felt black spot was the most threatening disease to roses $[41 \%(831)]$ in their gardens. When cross tabulating to identify the success rate of those respondents who were not members of rose organizations in identifying diseases correctly, fewer were successful, with 58\% (504) recognizing black spot, 54\% (469) identifying powdery mildew, and $61 \%$ (531) familiar with rust. Furthermore, fewer respondents who were not members of a rose organization felt black spot was the most threatening disease of roses [26\% (226)].

When ranking statements regarding the value of roses to the landscape, most [64\% (977)] of respondents strongly agreed or agreed that roses were the most valuable plants in their garden, and most $[53 \%(813)]$ agreed or strongly agreed that they would be willing to pay more for rose plants in their garden compared with what they would pay for other landscaping plants (Table 2).

When ANOVA comparisons were made to distinguish differences between members and nonmembers of rose associations regarding pleasing rose plant characteristics and cultural requirements necessary to maintain plants, some differences were found (Table 2). Members of rose associations were more willing to agree on the necessity of spraying chemicals to maintain healthy rose shrubs, with $48.3 \%$ (420) agreeing or strongly agreeing to the statement, "the best way to keep my rose bushes healthy is to spray them" compared with $18.5 \%$ (123) of nonmembers. Not surprisingly, nearly twice as many members $[80.8 \%(700)]$ strongly agreed or agreed that roses were the most valuable plants in their gardens compared with nonmembers $[41.1 \%$ (275)]. When considering the statement, "I prefer roses that have fewer big blooms rather than many small blooms," members and nonmembers of rose associations both had more than $40 \%$ of respondents responding as neutral regarding the statement. However, within each group, the remaining respondents had opposing views with more members of rose associations tending to agree or strongly agree with the statement $[26 \%(312)]$, whereas nonmembers disagreed or strongly disagreed at a similar level [29.1\% (195)]. Members of rose associations strongly disagreed or disagreed more often $[65.6 \%(568)]$ with the statement, "roses are difficult to grow" when compared with nonmembers [57.4\% (384)]. It is notable that the majority of both groups tended to disagree with the statement and that a similar percentage of respondents in both groups agreed or strongly agreed with the statement [19.2\% (166) of members vs. $20.8 \%$ (139) of nonmembers]. However, nonmembers had more neutral responses $[21.8 \%$ (146)]. Lastly, members and nonmembers of associations had conflicting opinions regarding the statement, "I would pay more for a rose bush than I would for most other landscaping plants." Members of rose associations agreed or strongly agreed with the statement more often $[61.9 \%$ (536)] when compared with nonmembers $[41.1 \%(27.5)]$, whereas nonmembers disagreed or strongly disagreed with the statement more often [31.4\% (210) vs. 15.1\% (131)].

Multivariate ANOVA COMPARISONS AMONG DEMOGRAPHIC VARIABLES. No differences were found in preferences based on occupation of the respondents (all factors $P>0.05$ ). However, differences were found in comparisons among age groups on the importance of the following variables: flower color $(P<0.001)$, fragrance $(P<0.001)$, foliage color $(P=$ $0.038)$, and foliage glossiness $(P<$ $0.001)$.

Those gardeners in their $70 \mathrm{~s}$ responded similarly but different from all other age groups in preference for flower color. Nearly $80 \%$ (240) of responses chose their favorite rose flower color as being red to red-orange. Younger gardeners were more likely to consider other colors of roses and spread out their preferences among the other color options of blue, lavender, pink, yellow, and orange.

Preference for fragrance varied with it being more important to those gardeners aged in their 40s, 50s, and 60 s, where $56 \%$ to $65 \%(90-371)$ or more of respondents within these age categories said this was somewhat or very important to them in their perceptions of the value of a rose. This variable was rated less often in those categories by those older than 80 years $[42 \%(30)]$ or those in their 20 s $[26.9 \%(28)]$ and 30 s $[43.7 \%$ (45)].

Gardeners in most groups responded that foliage color and foliage glossiness were neutral to unimportant compared with other variables. Foliage color was listed as neutral to unimportant by $52 \%$ (53) of people aged in their $30 \mathrm{~s}, 58 \%(80)$ people in their 40s, and $63.9 \%$ (248) of people in their 50s. However, younger gardeners ranked it as being a neutral category more often compared with those older gardeners ranking it as unimportant. Foliage glossiness was listed similarly as neutral to unimportant by $45 \%$ (46) of people in their 30 s and $58 \%$ (80) in their 40s.

Qualitative comments. Comments from survey respondents supported quantitative ideas gathered but also brought up other considerations not identified within the choice of questions/answers in the survey. For instance, comments supporting 


\section{Research Reports}

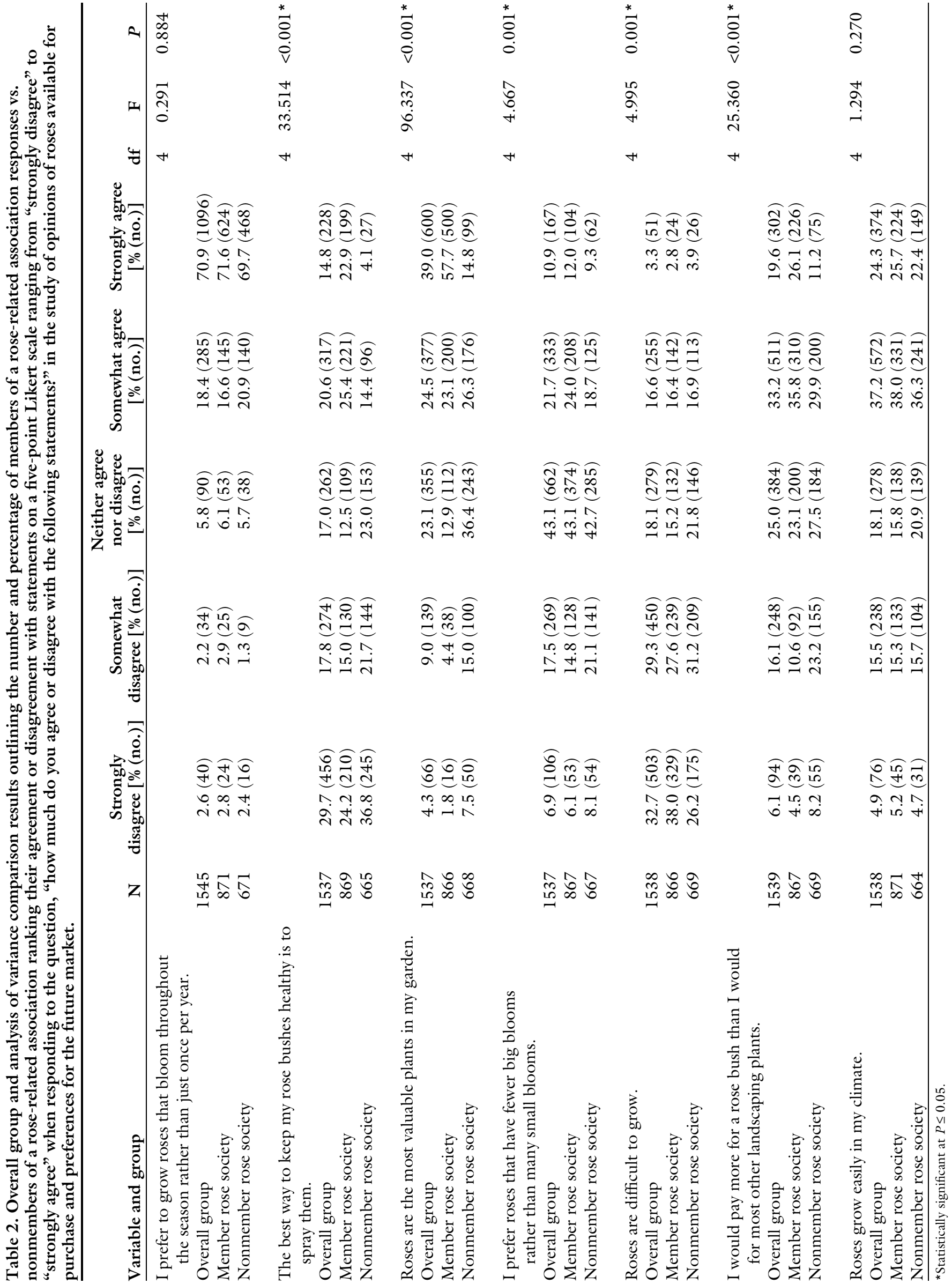


the idea of a need for disease resistance were reflected in the comment, "old-fashioned roses allow for disease-resistance and easy growth, so I lean towards growing those." The desire for fragrance was reflected in the note, "breed fragrance back into our roses, please!"

Other qualitative remarks indicated that the pest problems mentioned did not address some additional issues consumers were having such as the following: "there was no mention of virus problems, which to me are high on the list since viruses cannot be treated by the consumer," and "I noticed that winter hardiness was a choice for several questions but heat tolerance wasn't. I would have selected that as an important factor in choosing a rose if it were an option in the survey." Another reported, "deer keep me from growing roses.”

One respondent shared an opinion regarding the impact of the big-box store sales and their influence on cultivar availability with suggestions such as, "I think that lack of variety the big-box stores provide will probably cripple the industry in the long run." Another person mentioned, "I do wish that the industry stopped the rumor that roses are difficult to grow. Maybe in some areas they are, but for $\$ 20$ and a little love and care the rose blooms for at least 6 months of the year continuously while no other plant (flower) does, also for many, many years."

\section{Conclusions}

Results of the study will help direct future rose breeding efforts. This study found respondents preferred roses that were disease resistant, with fragrant, abundant, red, and everblooming flowers. The ideal height of the rose shrubs is waist to shoulder-height. Exceptions to preferences were noted among rose gardeners of different experience levels and ages. Qualitative comments provided support for the quantitative results and new unexpected ideas such as those relating to improvements related to heat, deer, and viruses.

Although these trends in this study are interesting to consider, ultimately they show that preferences vary within our target consumer groups and, therefore, marketing also may need to be adjusted based on the demographics of those living within a region or to draw a new market.
Millennials, those born between the 1981 and 1991 and reaching young adulthood at the beginning of the 21 st century (Merriam-Webster Inc., 2018), may prefer a different type of plant compared with a more mature gardener. Recent research has shown differences in floral expenditures in consumers younger than 40 years old and a need to determine their needs and effective marketing strategies (Zhao et al., 2016). Past research found differences in consumers of different ages in their garden purchase satisfaction and levels of purchase regret and encouraged differing marketing tactics based on age (Behe and Dennis, 2009).

These results also indicated respondents who were members of rose-related associations valued some particular characteristics more or less when compared with nonmembers of rose associations and had differing values and habits when managing roses. This information could be helpful in recognizing the needs and preferences of the average consumer vs. a more experienced rose grower and the value of reaching out to gardening associations to promote new products or management techniques.

\section{Literature cited}

Basye, R. 1992. Rose research at Texas A\&M-The future of the rose. Amer. Rose Annu. 31:62-63.

Behe, B., R. Nelson, S. Barton, C. Hall, C. Safley, and S. Turner. 1999. Consumer preferences for geranium flower color, leaf variegation, and price. HortScience 34: 740-742.

Behe, B. and J. Dennis. 2009. Age influences gardening purchases, participation, and customer satisfaction and regret. Acta Hort. 831:179-184.

Boumaza, R., L. Huché-Thélier, S. Demotes-Mainard, E. LeCoz, N. Leduc, and S. Pelleschi-Travier. El Mostafa Qannari, Sakr, S. P. Santagostini, R. Symoneaux, and V. Guerin. 2010. Sensory profiles and preference analysis in ornamental horticulture: The case of the rosebush. Food Qual. Prefer. 21:987-997.

Cucciniello, L. 2008. Rose to rosary: The flower of Venus in Catholicism, p. 64-65. In: F. Hutton (ed.). Rose lore: Essays in semiotics and cultural history. Lexington Books, Lanham, MD.

Debener, T. and D.H. Byrne. 2014. Disease resistance breeding in rose: Current status and potential of biotechnological tools. Plant Sci. 228:107-117.

Gall, M.D., J.P. Gall, and W.R. Borg. 2006. Educational research: An introduction. 8th ed. Allyn and Bacon, White Plains, NY.

Green Industry Research Consortium. 2013. Trade flows and market practices within the U.S. nursery industry, 2013. 10 Nov. 2018. <http://saaesd.ncsu.edu/ docs /National\%20Green\%20Industry\% 20Survey $\% 20$ report $\% 202014 \% 20$ SCSB $\%$ 2052615.pdf>.

Grygorczyk, A., S. Mhlanga, and I. Lesschaeve. 2014. The most valuable player may not be on the winning team: Uncovering consumer tolerance for color shades in roses. Food Qual. Prefer. 47: 23-28.

Guoliang, W. 2003. Ancient Chinese roses, p. 395-402. In: A.V. Roberts, T. Debener, and S. Gudin (eds.). Encyclopedia of rose science. Elsevier Academic Press, Amsterdam, The Netherlands.

Hopler, W. 2017. Sacred roses: The spiritual symbolism of the rose. 8 June 2018. <https://www.thoughtco.com/sacredroses-spiritual-symbolism-rose-123989>.

Hutton, S. 2012. The future of the rose industry. Amer. Rose Annu. 41:36-37.

Likert, R. 1967. The method of constructing an attitude scale, p. 90-95. In: M. Fishbein (ed.). Readings in attitude theory and measurement. Wiley, New York, NY.

Lombardini, L., T.M. Waliczek, and J.M. Zajicek. 2008. Consumer knowledge of nutritional attributes of pecans and factors affecting purchase. HortTechnology 18: $481-488$.

Merriam-Webster Inc. 2018. Millennial. 10 Nov. 2018. <https://www.merriamwebster.com/dictionary/millennial>.

Palma, M., C. Hall, and C. Collart. 2011. Repeat buying behavior for ornamental plants: A consumer profile. J. Food Distrib. Res. 42:67-74.

Pemberton, H.B., J.W. Kelly, and J. Ferare. 2003. Pot rose production, p. vi-vii. In: A.V. Roberts, T. Debener, and S. Gudin (eds.). Encyclopedia of rose science. Elsevier Academic Press, Amsterdam, The Netherlands.

Pemberton, B. and J.F. Karlik. 2015. A recent history of changing trends in USA garden rose plant sales, types, and production methods. Acta Hort. 1064:223234.

Short, K.C. and A.V. Roberts. 1991. Rosa spp. (roses): In vitro culture, micropropagation, and the production of 


\section{Research Reports}

secondary products, p. 377-397. In: Y. P.S. Bajaj (ed.). Biotechnology in agriculture and forestry: Medicinal and aromatic plants III. Vol. 15. Springer-Verlag, Bern, Switzerland.

Sommerfeld, A.J., A.M. McFarland, T.M. Waliczek, and J.M. Zajicek. 2010. Growing minds: Evaluating the relationship between gardening and fruit and vegetable consumption in older adults. HortTechnology 20:711-717.
U.S. Department of Agriculture. 2015. Floriculture crops 2015 summary. U.S. Dept. Agr., Natl. Agr. Stat. Serv. ISSN 1949-0917. 10 Nov. 2018. <http:// usda.mannlib.cornell.edu/usda/current/ FlorCrop/FlorCrop-04-26-2016. pdf>.

Widrlecher, M.P. 1981. History and utilization of Rosa damascene. Econ. Bot. $35: 42-58$.
Zhao, S., C. Yue, M. Meyer, and C. Hall. 2016. Factors affecting U.S. consumer expenditures of fresh flowers and potted plants. Hort Technology 26:484-492.

Zlesak, D.C. 2006. Rose, Rosa $\times$ bybrida L., p. 695-738. In: N.O. Anderson (ed.). Flower breeding and genetics: Issues, challenges and opportunities for the 21 st century. Springer, Dordrecht, The Netherlands. 